\title{
National responses to HIV/AIDS and non-communicable diseases in developing countries: analysis of strategic parallels and differences
}

\author{
Tilahun Nigatu Haregu, ${ }^{1}$ Geoffrey Setswe, ${ }^{2}$ Julian Elliott, ${ }^{3}$ Brian Oldenburg${ }^{1}$ \\ ${ }^{1}$ Department of Epidemiology and Preventive Medicine, Monash University, Melbourne, Australia; \\ ${ }^{2}$ School of Health Sciences, Monash University, Ruimsig, South Africa; ${ }^{3}$ Infectious Disease Unit, \\ Alfred Hospital, Melbourne, Australia
}

Significance for public health

This study explores the parallels and differences between national responses to HIV/AIDS and non-communicable diseases (NCDs). The identified parallels can be the basis for integrated response to HIV/AIDS and NCDs. In contrast, the important differences are essential for maintaining the integrity of the responses to HIV/AIDS and NCDs in the process of integration.

\section{Abstract}

HIV/AIDS and non-communicable diseases (NCDs) epidemics may have many important similarities in their aetiology, pathogenesis and management. Evidence about the similarities and differences between the national responses HIV/AIDS and NCDs is essential for an integrated response. The objective of this study was to examine the parallels and differences between national responses to HIV/AIDS and NCDs in selected developing countries.

This study applied a strategic level comparative case study approach as its study design. The main construct was national response to HIV/AIDS and NCDs. The 4 overarching themes were policy response, institutional mechanism, programmatic response and strategic information. Four countries were purposively selected as cases. Data were collected and triangulated from a multiple sources. The focus of analysis included identifying items for comparison, characteristics to be compared, degrees of similarity, and strategic importance of similarities. Analysis of data was qualitative content analysis with within-case, between-case, and across-case comparisons.

While the nature of the disease and the contents of national HIV/AIDS and NCD policies are different, the policy processes involved are largely similar. Functional characteristics of programmatic response to HIV/AIDS and NCDs are similar. But the internal constituents are different. Though both HIV and NCDs require both a multi-sectorial response and a national coordination mechanism, the model and the complexity of the coordination are different. Strategic information frameworks for HIV/AIDS and NCDs use similar models. However, the indicators, targets and priorities are different. In conclusion, the national responses between HIV/AIDS and NCDs are largely similar in approaches and functions but different in content.

\section{Introduction}

On top of the already existing burden of communicable diseases, maternal and child health problems and injuries/accidents, the epidemic of non-communicable diseases (NCDs) is a new additional pub- lic health threat to most developing countries. ${ }^{1}$ Since the beginning of HIV epidemic, about 70 million people have been infected by the virus and 35 million people have died due to the virus. At the end of 2011, about 34 million people were living with HIV. An estimated $0.8 \%$ of adults aged 15-49 years are living with the virus. About 1.7 million people died of AIDS-related illnesses worldwide in 2011. Sub-Saharan Africa accounts $69 \%$ of people living with HIV worldwide. About 1 in 20 adults in Sub-Saharan Africa (4.9\%) are living with the virus. ${ }^{2}$ NCDs kill more than 36 million people every year. About $80 \%$ of NCD related deaths (29 million) occur in low-and-middle income countries. More than 9 million NCD related deaths occur before 60 years of age. The majority (90\%) of premature NCD deaths occur in low and middle income countries. Four common NCDs (cardiovascular diseases, cancers, chronic respiratory diseases, and diabetes) account for $80 \%$ of all NCD related deaths. These four common NCDs share four major risk factors: tobacco use, physical inactivity, harmful use of alcohol and unhealthy diet. ${ }^{3}$ Development, industrialization, urbanization, investment, and aging are the major drivers of the NCD epidemic in those countries. ${ }^{4}$

In addition to their epidemiological overlap in developing countries, HIV/AIDS and NCDs share many additional commonalities that are related to their causation (aetiology), progression (pathogenesis), and response (prevention and control). Evidence about these inter-relationships is essential for the planning and implementation of coordinated and/or integrated programs. ${ }^{5}$ From the viewpoint of risk factors, HIV/AIDS is mostly related to most-at-risk and vulnerable populations and are at higher risk of being infected or affected by HIV [most-atrisk and vulnerable populations includes commercial sex workers (CSW), men having sex with men (MSM), intravenous drug users (IDUs) and bridge population (Migrant workers and long distance truck drivers)]. Examples include unprotected sex with a partner whose HIV status is unknown, multiple sexual partnerships involving unprotected sex, and injecting drug use with contaminated needles and syringes. ${ }^{6}$ Key populations for HIV vary based on context. The most common key populations include people living with HIV, their partners and families, people who sell or buy sex, men who have sex with men, people who use drugs, orphans and other vulnerable children, certain categories of migrants and displaced people and prisoners. ${ }^{7}$ The common NCDs (cardiovascular disease, cancers, diabetes and chronic respiratory disease) are associated with four common behavioural and lifestyle risk factors (unhealthy diet, insufficient physical activity, tobacco use, and harmful use of alcohol). ${ }^{8}$ The similarities and differences between the global responses to HIV/AIDS and NCDs have already been explored. ${ }^{9}$ Largely influenced by the global level responses, national level responses to HIV/AIDS and NCDs apply a multi-sectorial approach and whole-of-government efforts in order to mitigate the multi-faceted risk factors and impacts of the problems. ${ }^{10,11}$ The implementation of such approaches needs well-coordinated 
policies/strategies and systems. As intervention against either HIV/AIDS or NCDs will affect the other, intervening jointly against HIV/AIDS and NCDs, rather than competing for limited funds, is an essential policy approach that requires innovative models and approaches. $^{12}$

Although the similarities between HIV/AIDS and NCDs in risk factors, progression and management are known, the similarities and differences between national level responses to them are not well investigated. ${ }^{9}$ Though the specific behavioural entities involved are different, this signifies the importance of behavioural dimension in the risk factors of both HIV/AIDS and NCDs. ${ }^{13}$ Evidence from the analysis of the parallels and differences between the national response to HIV/AIDS and NCDs is useful in pinpointing potential areas of integration and differentiation. Therefore, this study was designed to examine the strategic level parallels and differences between national responses for HIV/AIDS and NCDs in selected developing countries and emerging economies.

\section{Scope of the study}

The major construct of this study was the national (strategic) level response to HIV/AIDS and NCDs. Adapted from the World Health organization's Health system framework; the overarching themes were policy response, programmatic response, institutional mechanism, and strategic information. ${ }^{14}$ These themes were assumed to be inter-locked constituents of the main construct. Information related to the magnitude, determinants, trends, and distribution of the problems was used for the purpose of context setting.

Figure 1 shows the conceptual framework of this study. Coordination is the key element of multi-sectoral response to HIV/AIDS and NCDs as all major response functions require strong national level coordination. As indicated in the framework, country level responses are shaped by both global responses including MDGs and local contexts like local epidemiology of the diseases.

\section{Study design}

This study was a comparative case study. A case study approach was used as the main focus was on how countries are responding to the epidemics. Besides, there was a need to uncover contextual factors.

\section{Selection of cases and study setting}

The selection of countries was purposive (maximum variation) based on in the combined cluster analysis of epidemiological trends of prevalence of HIV/AIDS and Diabetes from a study that identified four clusters of countries. ${ }^{15}$ One country from each cluster was selected based on ease of access to data sources. The selected countries are South Africa (17.3\% HIV and 6.5\% diabetes prevalence), Malaysia ( $0.4 \%$ HIV and $11.7 \%$ diabetes prevalence), Sri Lanka (0.1\% HIV and $7.8 \%$ diabetes prevalence), and Ethiopia (1.4\% HIV and 3.4\% diabetes prevalence) ${ }^{16,17}$ Malaysia and South Africa are upper middle income countries. Sri Lanka is a lower middle income country. Ethiopia is a least developed country.

\section{Data collection}

Multiple data sources were used in this study. These included policy documents, performance reports, databases, surveys reports and peerreviewed literature. The primary policy documents reviewed were the most recent Health, HIV/AIDS, and NCD policies/strategies which were available in the public domain. Most recent annual health sector and HIV/AIDS were among the reports reviewed. This study also draws on publicly available NCD related data collected in 2010 from the Ministries of Health of countries as part of the WHO sponsored global key-informant surveys. ${ }^{18}$ The data contains variables related to the capacity of countries to respond to HIV/AIDS and NCDs in five areas: public health infrastructure; the status of policies, strategies, action plans and programmes; health information systems, surveillance and surveys; the capacity of health care systems for early detection, treatment and care; and health promotion, partnerships and collaboration. Information from global and national level survey reports and other peer-reviewed literature relevant to health systems response to HIV/AIDS and NCDs with special reference to the case countries was also used.

\section{Data collection tools}

Using the four overarching themes, a data abstraction template was developed. Theme-based matrices were independently populated for each of the countries and the disease conditions. All the NCD data from Global Health observatory (2010) collected from the four case countries was extracted and included in this study.

The themes and sub-themes of the study are: i) problem description: magnitude of the problem, risk factors for the problem, historical overview of the response; ii) policy response: policy making bodies, policy frameworks, policy interventions; iii) programmatic response: prevention, treatment, care and support, cross-cutting areas (capacity building, health system strengthening etc.); iv) institutional mechanism: institutional structures (actors - state and non-state, and partners), national coordination mechanism; v) strategic information:

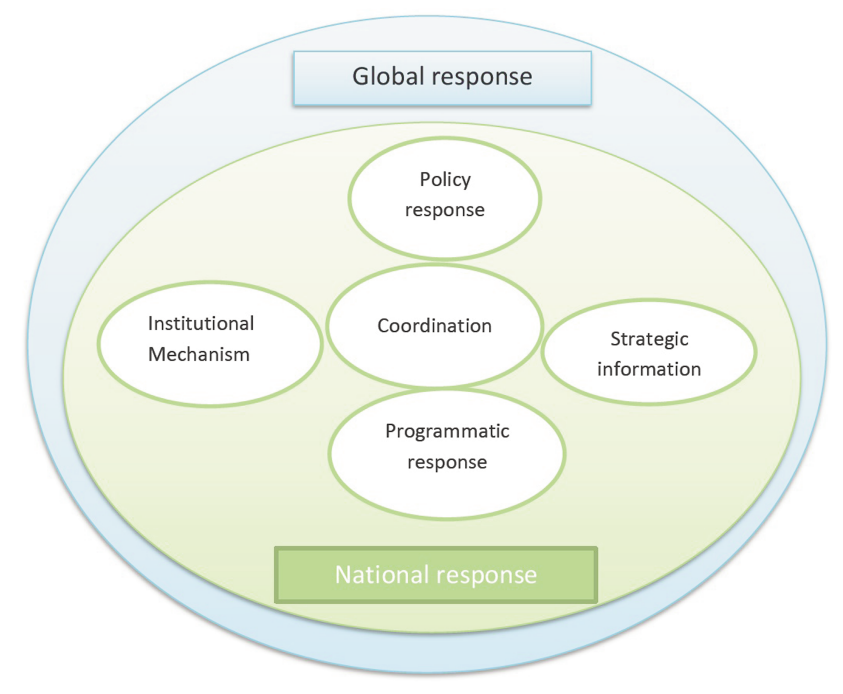

Figure 1. Conceptual Framework of the study: broken lines show the fact that national responses are shaped by global responses; the circles show the major elements of national response. 
monitoring and evaluation systems, surveillance systems, monitoring and evaluation interventions.

The sub-themes were used as categories in the coding process.

\section{Data analysis and management}

The overall analysis was a qualitative content analysis approach. Comparative analysis of strategic parallels within a country (withincase), comparison of strategic parallels of a disease between different cases (between-disease), and comparison of strategic parallels across all the cases and the two disease conditions (cross-case) were used. In this process, items to be compared were the core components of the response. The focus of analysis included identifying items for comparison, characteristics to be compared, degrees of similarity, and strategic importance of similarities. Findings were summarized using integrative synthesis. ${ }^{19}$

\section{Problem description}

\section{Magnitude of HIV/AIDS and non-communicable dis- eases}

HIV/AIDS is a generalized epidemic in South Africa and Ethiopia but a concentrated epidemic in Malaysia and Sri Lanka. NCDs cause more deaths than HIV/AIDS in all the case countries except South Africa.
Table 1 illustrates, NCDs accounts about one-third of total annual deaths in South Africa and Ethiopia but about two-third of total annual deaths in Malaysia and Sri Lanka. ${ }^{20,21}$ However, it would be important to consider age at death in the comparison of HIV and NCD related deaths. HIV related deaths generally occur at a lower age than that of NCDs. Thus, HIV related deaths are associated with higher DALYs.

\section{Risk factors for the problem}

Heterosexual intercourse is the main driver of HIV epidemics in all case countries. Intravenous Drug Users (IDU) and Men having Sex with Men (MSM) are more important in Sri Lanka and Malaysia. The burden of HIV/AIDS is higher among Females in South Africa and Ethiopia; but in Males in Malaysia and Sri Lanka. NCDs risk factors and risk groups have mixed picture in the case countries: South Africa and Malaysia have high rates for tobacco smoking, physical inactivity, and obesity as compared to Sri Lanka and Ethiopia. Magnitude of raised blood pressure and raised blood glucose are more or less similar across the case countries (Table 2). ${ }^{20}$

\section{Historical overview of the response}

The history of national response to HIV/AIDS started in the late 1980s or early 1990s (Table 3). National level policy/strategy/plan was formulated and national coordinating mechanism (NCM) was established during those years. National HIV/AIDS responses in the case countries have gone through at least three strategic periods. ${ }^{22}$

Table 1. HIV/AIDS and non-communicable diseases profiles of the case countries, 2011.

\begin{tabular}{lcccccc} 
Country & HIV prev. \% & AIDS prev. \% & PLHIV & HIV deaths & NCD deaths & NCD deaths \% \\
South Africa & 17.3 & 15.9 & $5,600,000$ & 270,000 & 190,600 & 29 \\
Sri Lanka & $<0$. & $<0.1$ & 4200 & $<500$ & 117,900 & 65 \\
\hline Malaysia & 0.4 & 0.4 & 81,000 & 5900 & 89,500 & 67 \\
Ethiopia & 1.4 & 3.6 & 790,000 & 54,000 & 338,300 & 34 \\
\hline
\end{tabular}

NCD, non-communicable diseases.

Table 2. Prevalence of common non-communicable diseases risk factors in the case countries (2011).

\begin{tabular}{lccccc} 
Country & Daily tobacco smoking & $\begin{array}{c}\text { Physical inactivity } \\
(\%)\end{array}$ & $\begin{array}{c}\text { Raised blood pressure } \\
(\%)\end{array}$ & $\begin{array}{c}\text { Raised blood glucose } \\
(\%)\end{array}$ & $\begin{array}{c}\text { Obesity } \\
(\%)\end{array}$ \\
South Africa & 14 & 51.1 & 42.0 & 10.6 & 31.3 \\
Sri Lanka & 10.6 & 26.0 & 39.2 & 10.5 & 5.1 \\
\hline Malaysia & 21.5 & 60.5 & 34.7 & NA \\
Ethiopia & 2.4 & 17.9 & 35.2 & 14 \\
\hline
\end{tabular}

NA, Data not available.

Table 3. Milestones in the history of national response to HIV/AIDS and non-communicable diseases.

\begin{tabular}{lccc} 
& South Africa & Sri Lanka & Malaysia \\
First HIV/AIDS case reported & 1982 & 1986 & 1986 \\
First HIV/AIDS NCM & 1992 & 1986 & 1984 \\
\hline First HIV/AIDS national plan & 1994 & 1996 & 1985 \\
First Integrated NCD plan & 2013 & 2009 & 1988 \\
\hline
\end{tabular}

NCM, national coordinating mechanism; NCD, non-communicable diseases. 
Integrated national response to NCDs started during the past five years. However, disease-specific NCD responses were in place for years, although they received very little attention. Though NCDs were included in the sector-wide strategies and were being addressed by the sector-wide structures for years, integrated national responses to NCDs are either at the first strategic period. ${ }^{23}$

\section{Policy response}

Policy responses to HIV/AIDS and NCDs in this study include the incorporation of HIV/AIDS and NCDs in to sector-wide policies, the development of separate HIV/AIDS and NCD policies, and the rollout of policy/regulatory interventions that are important to curb the tide of the epidemics. All these require complex processes with a wide range of consultations and deliberations. Moreover, they are highly influenced by global policies.

\section{Policy processes}

Analysis of the policy-related processes involved in the national response to HIV/AIDS in the case countries has revealed four major processes. The first one is political leadership which involves the highest political bodies of a country (Cabinet/members/Ministers/President etc.). The second process is policy making process that involves drafting (and approving) policies and overseeing its implementation. The third process is policy advisory role that addresses policy and technical issues and plays advisory role on policies and technical issues. The final process is program governance which is usually provided by National (HIV/AIDS) secretariat/working group/taskforce (members) ${ }^{24-27}$ With regard to NCDs, all four case countries have a responsible body in the Ministry of Health responsible for NCDs. NCD specific policy processes and governance structures vary widely across countries. South Africa has started establishing a National Health Commision to be chaired by the presidency and involving all relevant government sectors and others. In addition, it has established an advisory committee on the prevention and control of cancer in January 2013. South Africa also has inter-ministerial committee on prevention of substance abuse. The department of health currently has lead role in presenting a bill on control of the marketing of alochol. Sri Lanka has National Health Council for promoting collaboration, and National NCD steering committee for monitoring policy implementation. Malaysia proposed Cabinet Committee for Health Promoting Environment chaired by Deputy Prime Minister and involves the major ministries. In Ethiopia, a National Technical working group drafted the strategic framework for the prevention and control of NCDs. A national level NCD consortium is also established. ${ }^{28-32}$

\section{Policy frameworks}

Both HIV/AIDS and NCDs are included in the health sector policies in all the case countries. The 10 point NHS of south Africa, the $4^{\text {th }}$ HSDP of Ethiopia, the 10 year Health Master plan of Sri Lanka, and the $10^{\text {th }}$ Country Health Plan of Malaysia all have included both NCDs and HIV. ${ }^{33-36}$ Besides, all the case countries have stand-alone policy/strategy frameworks for both HIV/AIDS and NCDs: at least the $3^{\text {rd }}$ for HIV and the $1^{\text {st }}$ for NCDs. Based on the data from Global Health Observatory (GHO), though the mix varies, all the countries have NCD related policies/strategies. Case countries also have HIV policies specific to some population groups, and specific technical areas. South Africa and Sri Lanka have operational policy documents on the four major NCDs and the four common NCD risk factors. At the time of this study, we haven't found specific operational policy document on diabetes and aclohol from Malaysia. At the time of this study, Ethiopia hasn't yet launched an operational policy/strategy/action plan on the four major NCDs and four common NCD risk factors.

There are concerns in the alignment of HIV/AIDS and NCD specific policies/strategies with the sector-wide policies/strategies. The alignment of NCD specific policies with disease/risk factor specific policies is also another area of concern in the integrated response to NCDs. Different types of Tobacco Acts are available in the case countries. At the time of this study, all the case countries except Ethiopia have ratified the WHO Framework Convention on Tobacco control (FCTC). Food Acts and Nutrition policies/strategis also exist in the case countries. Stand-alone policy frameworks for promotion of physical activity in the case countries were not identified in this study. South Africa has recently developed a policy addressing cervical cancer. The most recent policy frameworks for HIV/AIDS and NCDs are listed in Table 4.

\section{Policy/regulatory interventions}

HIV/AIDS policy/regulatory interventions focus on right, equity and justice related to HIV programming and People living with HIV. On the other hand, policy/regulatory interventions of NCDs focus on the use of policies to reduce exposure to the risk factors (regulatory measures) such as tobacco smoking, alcohol use and consumption of high calorie foods. Gender-based violence and discrimination got more attention in HIV/AIDS response as they are more related to HIV. Mandatory NCD screening for employees is being implemented in Malaysia. Malaysia has developed a guideline to control marketing of food and alcoholic beverages to children. Our review of documents shows that reporting cancer has been made compulsory by regulation in South Africa. Regulations to reduce salt content in specified foods are gazetted in South Africa. Regulations on trans-fatty acids have already been in practice since 2011 in South Africa. Our literature search hasn't found such regulations in in Sri Lanka and Ethiopia.

Table 4. List of most recent HIV/AIDS and non-communicable diseases policy frameworks.

\begin{tabular}{|c|c|c|}
\hline Country & HIV/AIDS & NCD \\
\hline South Africa & National strategic plan on HIV, STIs and TB: 2012-2016. ${ }^{24}$ & South African NCD action plan 2013-2016. ${ }^{32}$ \\
\hline Sri Lanka & National HIV/AIDS strategic plan: 2013-2017. ${ }^{27}$ & $\begin{array}{l}\text { The National Policy \& Strategic framework for Prevention \& Control } \\
\text { of chronic NCDs, 2009.28 }\end{array}$ \\
\hline Malaysia & National Strategy Plan on HIV and AIDS: 2011-2015. ${ }^{26}$ & National Strategic plan for NCDs: 2010-2014. ${ }^{29}$ \\
\hline Ethiopia & $\begin{array}{l}\text { Strategic plan for intensifying Multi-sectoral } \\
\text { HIV and AIDS response in Ethiopia: } 2010 / 11-2014 / 15{ }^{25}\end{array}$ & $\begin{array}{l}\text { Prevention and Control of Chronic NCDs: } \\
\text { Strategic Framework: Nov 2010.30 }\end{array}$ \\
\hline
\end{tabular}

NCD, non-communicable diseases. 


\section{Programmatic response}

Evidence from the case countries indicated that integrated NCD programs are not well instituted. Most of the existing NCD interventions are either sector-wide or disease/risk factor specific interventions. In the sector-wide interventions adequate priorities are not accorded to NCDs. As funding and donor interest in NCDs is generally low, disease/risk factor specific interventions are small and fragmented. In contrast, HIV/AIDS responses have attracted more resources and several sector-wide and HIV/AIDS specific programs have been implemented. However, most of the funding for HIV/AIDS was from external sources. Using these resources, several intervention protocols and guidelines have been developed and rolled out for the implementation of HIV/AIDS programs. ${ }^{37-40}$

\section{Prevention of HIV/AIDS and non-communicable diseases}

Both HIV/AIDS and NCD prevention strategies in the selected countries has been on behaviora//life style, structural, biomedical/biological, and policy/regulatory dimensions. Apart from Ethiopia, the other case countries have implemented fiscal interventions to influence behavior change and have earmarked taxes from fiscal interventions to influence behavior change used to fund health promotion programmes or a health promotion foundation. Individual, community-based, and institution-based approaches are used in the prevention approaches of both HIV/AIDS and NCDs. Most of the stakeholders (actors) in both HIV/AIDS and NCDs are those outside the healthcare system and includes several government sectors, NG0s, CBOs, FBOs etc. For instance, both HIV/AIDS and NCDs are integral to the school health program in South Africa. Influencing individual decision (to practice safe sexual behavior in case of HIV and to eat healthy foods, to stop smoking, to reduce alcohol or to improve physical activity; or to get screened/tested) is the ultimate goal of most of the prevention programs.

Malaysia has expanded communication for behavioral impact program for dengue to also include NCDs. It has also appointed a Malaysia Health Ambassadors to encourage Malaysians adopt healthy lifestyles. The country has also introduced an NCD risk factor intervention program - NCD prevention a Malaysia Program - in communities, workplace and schools. Media players are also actively engaged in NCD prevention interventions. Ministry of Health agreed to implement a new healthy eating guideline in schools

However, there are also essential differences in the prevention of HIV/AIDS and NCDs. Most of these differences emanate from the disease characteristics and epidemiology of HIV/AIDS and NCDs. Firstly, the main target populations for HIV/AIDS prevention are youth (15-24 years) and key populations (most at risk populations). ${ }^{41}$ But the main target population considered in most NCD prevention are adults $(>30$ years of age). Secondly, the purpose of HIV/AIDS prevention programs is to reduce transmission and vulnerability while that of NCDs is to reduce the risk of developing NCDs. Thirdly, the content (package) of the prevention programs is different. The contents of HIV/AIDS prevention programs are geard towards reducing the risk of transmission of the virus through sexual, parenteral and/or vertical routes while that of NCDs are geard towards reducing the common NCD risk factors and adopting healthy lifestyles. Lastly, the socio-cultural contexts surrounding HIV/AIDS prevention and NCD prevention are different. HIV/AIDS risk factors, mainly high risk sexual behaviors, are generally considered to be more sensitive than that of NCD risk factors.

South Africa, which managed to screen 13 million people for HIV, has acknowledged that HIV testing offers an excellent opportunity for NCD screening and thus has instructed that health testing must become comprhensive so that NCDs are tested at the same time as HIV and TB.
This country has also made a decision to provide Human Papiloma Virus (HPV) vaccine to pre-pubescent girls. In Ethiopia, a screening project for Gestational Diabetes was implemented together with the PMTCT program in healthcare facilities. As women on HIV/AIDS treatment may have higher risk of gestational diabetes, this project was considered to be exemplary. Healthy Lifestyle Centers (HLCs) in Sri Lanka are other examples of integrated prevention approaches.

\section{Treatment of HIV/AIDS and non-communicable diseases}

As the history of implementation of national treatment programs of HIV/AIDS and NCDs are very different, the main priorities of HIV/AIDS and NCD treatment strategies are also different. The main priorities of HIV/AIDS treatment programs are ensuring universal coverage to treatment for all eligible PLHIV and improving the quality of treatment programs. In contrast, the priorities of NCD treatment strategies are to increase availability of drugs and improve accessibility of treatment services. However, as both HIV/AIDS and NCDs are chronic diseases, the delivery of HIV/AIDS and NCD treatment services have the following charactorstics in common. Both require strong health systems and skilled multi-disciplinary health teams. Both need long-term monitoring and follow up. Both HIV/AIDS and NCD treatment also require adjacent prevention interventions, positive health, dignity and prevention (PHDP) for HIV/AIDS and improved health behavior/life style/ for NCDs. Based on data from Global Health Observatory guidelines for the management of diabetes and hypertension were available and implemented in all the case countries except Ethiopia. Most of the NCD tests were not available at primary health care level in Ethiopia. In the other three countries, at least half of the basic NCD tests were available at primary healthcare level. Regarding the general availability of NCD related medicines in the public health sector, Ethiopia has less than one fourth of the drugs considered for assessed while the other three countries have more than fourth-fifth of the drugs included in the list for the assessment. Assessment of the general availability of NCD related procedures (renal photocoagulation, renal replacement therapy, radiotherapy and chemotherapy); Ethiopia didn't have any of these. Malaysia has all the four, South Africa had all except renal replacement therapy, and Sri Lanka had all except renal photocoagulation. A symptom-based NCD diagnostic tool (known as primary care 101) is being developed in South Africa where NCDs are included in primary care package.

National Cancer Institute is a premier tertiary level hospital for diagnoses and treats cancer cases in Sri Lanka. Access to cancer treatment is limited. In rural areas, traditional healers have greater roles. In South Africa, only tertiary (specialised) hospitals and some private medical centres have cancer treatment facilities. In Ethiopia, where cancer is considered as a death sentence, there is only one cancer treatment centre for the whole population. In Sri Lanka and Malaysia, there are a few more cancer treatment centres.

\section{Care and support for HIV/AIDS and non-communica- ble diseases}

We have looked in to four major areas of care and support strategies for HIV/AIDS and NCDs: Continuity of care, control of disease progression, prevention of complications and integration of care services. Continuum of care for both HIV/AIDS and NCDs involves the patient, peers, family members, community systems and healthcare systems. Patient participation is important in both cases. In order to control disease progression, care and support programs of both HIV/AIDS and NCDs work for retaining patients in care with adequate treatment adherence. Both HIV/AIDS and NCDs are associated with a range of complications including co-infections and comorbidities. Accordingly, prevention of these complications is among the major priorities of care and support programs for HIV/AIDS and NCDs. Effective and efficient 
provision of care and support services also require integration of services along the continuum and across the components.

HIV/AIDS Care and support programs often include care for orphan and vulnerable children and economic strengthening activities that are intended to reduce vulnerability. They also consider stigma and discrimination as a major area of focus. NCD care and support programs often include healthy ageing as its focus area. Self-care is considered to be more important in NCD care and support strategies. In both HIV/AIDS and NCD care, improving the quality of life patients through better adherence to recommended treatment and retention in care is considered to be a key strategy. Promoting positive living and decreasing risk of infectivity are relevant elements of HIV/AIDS care and support programs. Apart from generic strategies for NCD related care, countries also have disease specific care guidelines for specific NCDs (e.g. diabetes care guideline in South Africa).

\section{Cross-cutting technical areas}

The main crosscutting programmatic responses stated in both NCD and HIV policy documents are capacity building, Health System Strengthening (HSS), mainstreaming, partnerships and empowerment. HSS and reform is one of the three NCD strategies in South Africa. An important initiative of this is the development of integrated chronic disease (both communicable and Noncommunicable) management model in three districts. We considered that the capacity building and HSS interventions should focus on both disease-specific (HIV/AIDS and NCD) structures (for technical and analytical capacity) and sectorwide structures (for program planning, implementation, monitoring and evaluation capacity).

The capacity building and HSS interventions, however, seem to provide more weight to on HIV/AIDS and NCD specific structures and functions rather than sector-wide structures and functions. As mainstreaming of interventions is mainly to government sectors, most of the government sectors may end up in having both HIV/AIDS and NCD related activities. Both HIV/AIDS and NCD responses involve broader partnership frameworks though the types of individual partners vary. Empowerment of community is another important area of focus of national responses to HIV/AIDS and NCDs in the case countries.

\section{Institutional mechanisms}

\section{Institutional structures for HIV and non-communica- ble diseases response}

Institutional structures involved in the national response to HIV/AIDS and NCDs are of two categories: actors (state and non-state), and partners. For HIV, these can be further classified in to sector-wide structures, and HIV-specific structures. For NCDs the list includes sector-wide structures, NCD-specific structures (integrated), disease-specific structures (individual NCD) and risk factor specific structures (individual risk factors). Currently, the state actors for HIV/AIDS are the majority of government ministries/departments/bureaus/agencies. Despite the principle that NCD response is a whole of government and whole of society effort, most of state actors for NCDs are agencies whose roles are directly related to the common NCD risk factors: unhealthy diet, physical inactivity, tobacco use, and alcohol use. With regard to the non-state actors, the national responses to HIV/AIDS involve several UN agencies, Non-govermental organizations and civil society organizations. Most of these structures are currently engaged in either technical/finacial support and/or implementation of HIV/AIDS programs. On the other hand, non-state actors involved in the national response to NCDs are mostly disease and risk factor specifc civil society organization and networks/coalitions/consortiums who are involved in advocacy, training, service delivery and research.

In the national responses to HIV/AIDS in the selected countries, there is a strong partnership with international donors and technical partners. Some of these (e.g. global fund) requires a separate coordination mechanism. In HIV response, partnership is in action but duplication/overlap is a problem. In NCD response, partnership is in a form of working relations and is a future strategy. Resources for HIV response are mostly from external sources. Resources for future NCD response are currently lacking and are expected from external sources too.

The Ethiopian National NCD consortium is a platform established by civil society organizations working on NCDs. It provides an excellent opportunity to promote a coordinated national response to NCDs. The consortium is working closely with both governmental and non-governmental organizations.

\section{National coordination mechanisms}

As the response to both HIV/AIDS and NCDs is multi-sectoral and multi-stakeholder in nature, a national coordination mechanism is needed. The location of the National coordination mechanisms (NCM) and its relation with sector-wide structures vary across countries. The current NCM for NCDs in all the case countries are under Ministry (Department) of health although new NCMs have been proposed. In Malaysia and Sri Lanka and NCM for HIV/AIDS are also under Ministry of Health. In South Africa and Ethiopia, the NCM for HIV/AIDS response is accountable to a higher government body than the Ministry (Department) of Health. The role of the NCMs is more of Planning, coordination and implementation, and M\&E rather than a technical advisory one. A partnership forum for HIV in South Africa and Ethiopia has other partners as members of the advisory body. Establishment of NCD coordination networks seems the future direction of NCD actors.

The NCMs for national response to HIV/AIDS in the case countries are South African National AIDS Council (SANAC) in South Africa, National STD and AIDS Control Program (NSACP) in Sri Lanka, AIDS/STI sector of the Disease Control Division in Malaysia, and HIV/AIDS prevention and control offices (HAPCO) in Ethiopia. Similarly, NCD cluster (Department of Health), NCD Prevention and Control Unit (Ministry of Health), NCD section (Disease Control Division/Ministry of Health) and NCD focal unit (Ministry of Health) are the NCD mechanisms in South Africa, Sri Lanka, Malaysia and Ethiopia respectively.

\section{Strategic information}

Monitoring and Evaluation along with innovative research are the key HIV and NCD strategic areas in all the case countries. The three types of monitoring activities evident in this study are patient/clini$\mathrm{cal} /$ monitoring, disease/risk factor/ monitoring and program monitoring. As all these forms of monitoring are driven by the national programs, their stages of implementation are different for HIV/AIDS and NCDs in the case countries. But the NCD monitoring can learn from HIV monitoring. A study conducted in Ethiopia revealed that patient monitoring systems developed for HIV/AIDS programs could be adapted for NCDs. ${ }^{42}$

\section{Monitoring and evaluation systems}

The Health information system (HIS) in each of the case countries supports strategic, management and operational decisions in the entire health sector. The HIS is a result of combined efforts of many stakeholders including the Ministry of Health and National statistical offices. M\&E units in the NCM of HIV/AIDS response coordinate the M\&E of National Strategic Plans (NSP) using the concept of one 
national M\&E framework. The HIV/AIDS M\&E system is inter-linked with national HIS. Despite the presence of NCD strategic plans in all the case countries, the development of M\&E frameworks for NCDs is at early stage. South Africa has yset ten targets to be achieved by 2020 . Sri Lanka's strategic plan states indicators and their means of verification.

The flow of M\&E data in the case countries is as follows. In Sri Lanka's HIV response, all reporting units report directly to the Strategic Information Management (SIM) unit of National STD/AIDS control program. In Malaysia, the Malaysian AIDS Council (MAC) coordinates the report from Civil Societies and NGOs and reports to the National AIDS Program Secretariat at Minstry of Health. All government sectors directly report to the secretariat. In Ethiopia, government sectors report to Federal HIV/AIDS Prevention and control office while other implementors report to relevant structures at their level of implementation. In South Africa, Health facilities report to District AIDS councils, which report to provincial AIDS councils, which further report to SANAC. Government and civil society sectors will be reporting within their established structures at the different levels

Both national HIV/AIDS and NCD M\&E systems need to draw data from national health information system. The performance of HIV/AIDS and NCD M\&E systems is therefore directly related to national HIS. Similarly, interventions designed to strengthen HIV/AIDS and NCD M\&E systems will directly contibute to the national HIS. Both HIV/AIDS and NCD M\&E systems need to invest on national HIS. The requirements of HIV/AIDS and NCD M\&E systems shound fit with the capacity of the national HIS. HIV/AIDS indicators are well included in the National HIS of the countries. However, the current National HIS in the case countries are not responsive to NCD related indicators. Hypetension rate and Mental Health case load are captured in South African District Health Barometer. Hospital statistics in Sri Lanka has indicators on NCDs.

\section{Surveillance, surveys and registry}

ANC-based HIV sentinel surveillance, Behavioral Survey Surveillance (BSS) and Demographic Health Surveys (DHS) are the common forms of HIV/AIDS surveillance and surveys in the case countries. AIDS case reporting is also among the mechanisms used to monitor the status of the HIV/AIDS Epidemic. Surveillance systems for NCDs are at different stages in the case countries. Malaysia, Sri Lanka and South Africa have reported the existence of cancer registry and NCD risk factor surveillance. Both cancer registry and surveillance of NCD risk factors were not available in Ethiopia. South Africa has prepared a plan for comprhensive NCD surveillance. In the intrim, South African Health and Nutrition Examination Survey is expected to provide relevant information. Ethiopia has conducted NCD situatiobal assessment and is looking forward to conduct a baseline assessment of NCDs. There are generally three forms of NCD surveillance considered: risk factor surveillance (bio-behavioral), disease surveillance and case registry/reporting. The eligible population groups vary but the two M\&E systems can learn from each others - especially methods and techniques. Some general population surveys like DHS, in some countries, adress both HIV/AIDS and NCDs. In South Africa, a chronic disease register has been produced for implementation in public health facilities to ensure that NCDs are detected early and managed approproately.

In Malaysia, the National Health and Morbidity survey for NCD risk factors will be conducted every four years. Several NCD indicators are also included in the performance indicator sets of Ministry of Health. The National Diabetes registry is established to obtain epidemiological and clinical data of diabetes patients receiving treatment in healthcare facilities throught malaysia. It involves electronic collection of data and is made available online.

Table 5. Summary of the parallels and differences between national responses to HIV/AIDS and non-communicable diseases.

\begin{tabular}{|c|c|c|c|}
\hline & HIV/AIDS & Both HIV/AIDS and NCDs & NCDs \\
\hline Policy response & $\begin{array}{l}\text { 3rd or 4th strategic period. } \\
\text { Policy priorities are quality and sustainability. } \\
\text { Sector, population, program specific policies. }\end{array}$ & $\begin{array}{l}\text { Have responsible policy making } \\
\text { bodies and national policy framework. } \\
\text { Both are included in sector-wide policy frameworks. }\end{array}$ & $\begin{array}{l}\text { At early stage. Advocacy and instituting } \\
\text { systems are priorities. Disease, risk factor } \\
\text { specific policies. }\end{array}$ \\
\hline Prevention & $\begin{array}{l}\text { Youth and MARPs focused; aim to reduce } \\
\text { transmission; purpose is chaning sexual behavior; } \\
\text { more sensitive context; } \\
\text { human rights, equity and justice as interventions. }\end{array}$ & $\begin{array}{l}\text { Prevention approaches; intervention dimensions; } \\
\text { affecting individual decision is the } \\
\text { ultimate goal. Mostly outside the health sector. }\end{array}$ & $\begin{array}{l}\text { Adult focused; aims to reduce risk; } \\
\text { purpose is to change lifestyle; } \\
\text { less sensitive context; } \\
\text { regulatory measures as interventions. }\end{array}$ \\
\hline Treatment & $\begin{array}{l}\text { Coverage higher. Ensuring universal coverage and } \\
\text { impoving quality are the strategic priorities } \\
\text { indicated in the policy frameworks. }\end{array}$ & $\begin{array}{l}\text { Need strong health systems; } \\
\text { multidisciplinary health treams; } \\
\text { adjacent prevention; long duration of monitoring } \\
\text { and follow up. Adherence is key. }\end{array}$ & $\begin{array}{l}\text { Coverage low. Increasing availability and } \\
\text { accessibility of treatment services is the } \\
\text { main priority. }\end{array}$ \\
\hline Care and support & $\begin{array}{l}\text { Orphan and vulnerable children are concerns; } \\
\text { co-infections more common; } \\
\text { stigma and discirmination is a concern. }\end{array}$ & $\begin{array}{l}\text { Ensuring continuum of care, } \\
\text { control of disease, prevention of } \\
\text { complications and provision of integrated services. }\end{array}$ & $\begin{array}{l}\text { Comorbidities are more common; mostly } \\
\text { associated with ageing/aged care; }\end{array}$ \\
\hline Cross-cutting & $\begin{array}{l}\text { Strengthening HIV/AIDS specific } \\
\text { (technical and analytical capacity) } \\
\text { and sector-wide structures } \\
\text { (for management and implementation). }\end{array}$ & $\begin{array}{l}\text { Strengthening of sector-wide structures; } \\
\text { mainstreaming in to sectors; community } \\
\text { empowerment; partnership and cooperation }\end{array}$ & $\begin{array}{l}\text { Strengthening NCD specific structures } \\
\text { (technical and analytical capacity) }\end{array}$ \\
\hline $\begin{array}{l}\text { Institutional } \\
\text { arrangement }\end{array}$ & $\begin{array}{l}\text { Most of government sectors involved; } \\
\text { many NGOs and CSOs involved in implementation; } \\
\text { well established NCM; better funded. }\end{array}$ & $\begin{array}{l}\text { Involves both state and non-state actors as } \\
\text { well as partners; a multi-sectoral coordinating } \\
\text { structure is existing. }\end{array}$ & $\begin{array}{l}\text { Limitted government sectors involved; } \\
\text { CSOs involved in advocacy; NCM at early } \\
\text { phase; low funding. }\end{array}$ \\
\hline $\begin{array}{l}\text { Monitoring and } \\
\text { evaluation }\end{array}$ & $\begin{array}{l}\text { Target population are ANC mothers, } \\
\text { youth, and MARPs; stronger evidence } \\
\text { base; priorities are ensuring quality } \\
\text { and utilization of evidence }\end{array}$ & $\begin{array}{l}\text { Draws data from national Health information } \\
\text { system; risk factors and disease surveillance } \\
\text { as well as case registry }\end{array}$ & $\begin{array}{l}\text { Target population are adults; weak evidence } \\
\text { base; priorities are ensuring NCD } \\
\text { responsive information systems }\end{array}$ \\
\hline
\end{tabular}

NCD, non-communicable diseases 


\section{Discussion}

HIV/AIDS and NCD epidemics have many commonalities. Both HIV/AIDS and common NCDs have slow pace of progression. HIV/AIDS has a long asymptomatic stage. The asymptomatic stage lies between primary HIV infection and the development of AIDS. ${ }^{43}$ The risk of many NCDs is set during development of a person. Nutritional imbalance and exposure to environmental chemicals during development can increase NCD risk later in life. ${ }^{44}$ Most NCDs are associated with long-term and persistent exposure to the risk factors. Many NCDs also have pre-disease stages that may last for a number of years. ${ }^{45}$ Moreover, combinations of major NCDs and infections can interact adversely. Co-morbidities in HIV/AIDS and NCDs are also of great clinical and public health importance. ${ }^{46}$

In the early period, infectious disease, like HIV/AIDS, and NCDs were perceived to be largely different. But with the advent to treatment, HIV/AIDS has now turned out to be a chronic disorder, like many of the common NCDs. As both are chronic diseases, the response interventions to HIV/AIDS and NCDs share many similarities. Prevention strategies of both HIV/AIDS and NCDs are targeted at modifying known risk behaviours. Treatment and care interventions focus on controlling disease progression and improving quality of life through better adherence to treatment, frequent monitoring of biomarkers, and provision of social support. ${ }^{47}$ National responses to HIV/AIDS and NCDs are at different stages of maturity. As a result of this, the level of attention and priority given to HIV/AIDS and NCDs during the past three decades in developing countries are very different. These differences have shaped all the components of national response in different ways. In this regard, National responses to HIV/AIDS are at a higher level of maturity and thus the focus of HIV/AIDS policies are quality and sustainability. As a result of early stages of development, the current focuses of NCD policies are advocacy and instituting appropriate institutional systems. Though differences in stages of maturity of programs are recognized, NCD programs can learn a lot from the experiences of HIV programs. The programmatic responses to HIV/AIDS and NCDs are comprised of prevention, treatment, care and support and cross-cutting interventions. The main target population groups and the contents of interventions show higher level of differences than the approaches and models used in the delivery of interventions in the cases countries. Of great importance is the overlap between cross-cutting interventions of both HIV/AIDS and NCDs that mainly aim for strengthening sector-wide structures. In this regard, cross-cutting interventions are potential areas of integration.

Regarding instututional mechanisms, both HIV/AIDS and NCDs involve muti-sectoral and whole of goverment and whole of society efforts. Both require a country response coordinating mechanism at national level. The nature and complexity of the coordination mechanisms, however, are different. National HIV/AIDS response coordination mechanisms have the characteristics of agency while those of NCDs have the characteristics of network. This difference has an important implication in the integration of HIV and NCD responses with the overall health system inteventions.

The models and methods of strategic information of national responses to HIV/AIDS and NCDs share many similarities though the contents and priorities of the strategic information section of the responses have many essential differences. A summary of the parallels and differences between national responses is shown in Table 5 .

Information outlets for HIV/AIDS in the case countries include AIDS resource centers, websites of National Coordinating Mechanims, and telephone-based help/talk lines, and State and private media.
Information outlets for NCDs are mainly websites of civil society organizations engaged in NCD advocacy activities. Most of the avaialble information about NCDs is related to the magnitude of the problems and their risk factors. Information about the responses to NCDs are very limitted.

Emphasis is given to NCD specific and HIV/AIDS specific M\&E system and the sector-wide M\&E system in all the case countries. The main priorities of HIV/AIDS M\&E systems in the case countries is to strengthen existing M\&E systems in health facilities and to incorporate new systems for community-based monitoring and reporting. By doing this, the quality of HIV/AIDS information is expected to be improved. Among the M\&E priorities is instituting a culture of evidence-informed decision making i.e. the use of evidence for policy and programs.

In comparison, the main M\&E priorities related to NCDs is making the national HIS responsive to NCDs. These include incorporating NCDs in to national HIS, promoting the generation and utilization of NCD related evidence and instituting new methods of NCD monitoring and evaluation (e.g. surveillances, registry systems) as an integral part of national HIS.

The findings of this study have important implications for policy and practice. The main implication is the coordination of national responses to HIV/AIDS and NCDs in order to reduce duplication and overlap and maximize synergy and efficiency. This study has identified essential areas of focus for integrated response. One of these is the crosscutting interventionns that focus on strengethining health systems.

There are some limitations associated with this study. Firstly, this study is limited to the context of four purposively selected case countries. The countries have heterogeneous epidemiological and socio-economic contexts. Thus, the study findings are only analytically generalizable. Secondly, the analysis focuses on national level (macro-level) responses and may not reflect meso and micro-level situations in the case countries. Moreover, exploration of the differences between case countries was beyond the scope of this study. Thirdly, the study is limited to the five broader thematic areas and information extraction is limited to these thematic areas only. Besides, limitations related to data availability and quality as well as the value-nature of the analysis methods should be taken in to consideration in the interpretation of the findings.

\section{Conclusions and Recommendations}

While the content characteristics of HIV and NCD policies are different, the process characteristics involved are largely similar. The operational characteristics of programmatic response to HIV and NCDs are similar. But the internal constituents of the programmatic response are different. Though both HIV and NCDs require both a multi-sectoral response and a coordination mechanism, the models and complexity of coordination are different. Strategic information frameworks for HIV/AIDS and NCDs employ similar methods. However, the indicators, targets and priorities are different. In general, the parallels between the national responses between HIV/AIDS and NCDs are largely in process characteristics and the differences are in content characteristics. The differences in the nature of the diseases and the level of maturity of the responses explain the major differences. It will be wise to consider the parallels identified in this study as initial areas of focus for integrated response to HIV/AIDS and NCDs in low- and middleincome countries. We also recommend further and more detailed exploration of similarities and differences between the responses to HIV/AIDS and NCDs in specific countries. 
Correspondence: Tilahun Nigatu Haregu, Department of Epidemiology and Preventive Medicine, Monash University, The Alfred Centre, 99 Commercial Road, Melbourne Vic 3004, Australia.

Tel. +61.403.726.798

E-mail: tilahun.haregu@monash.edu

Key words: national response, HIV/AIDS, non communicable diseases, parallels, differences, public health policy.

Acknowledgements: we extend our acknowledgements to Monash University, the respective health sectors in the case countries and all individuals who helped us in availing the relevant information.

Contributions: TNH designed the study, wrote the protocol, collected the data, performed the analysis, and wrote the first draft of the manuscript; B0, $\mathrm{JE}$ and GS supervised the study and reviewed the manuscript.

Conflict of interests: the authors declare no potential conflict of interests.

Received for publication: 24 January 2014.

Accepted for publication: 28 February 2014.

(C) Copyright T.N. Haregu et al., 2014

Licensee PAGEPress, Italy

Journal of Public Health Research 2014; 3:99

doi:10.4081/jphr.2014.99
14. World Health Organization. The WHO health systems framework. Available from: http://www.wpro.who.int/health_services/health_ systems_framework/en/.

15. Haregu TN, Elliott J, Setswe G, Oldenburg 0. Epidemiological patterns of HIV/AIDS and NCDs in developing countries: a cluster analysis. Int J Tropic Dis Healt 2013;3:1-12.

16. UNAIDS. HIV/AIDS estimates. 2011. Available from: http://www.unaids.org/en/regionscountries/countries/.

17. Federation ID. Diabetes atlas 2012 update. 2012. Available from: http://www.idf.org/diabetesatlas.

18. World Health Organization. Data on health system response and capacity to address and respond to NCDs. Geneva: World Health Organization; 2010.

19. Sandelowski M, Voils CI, Leeman J, Crandell JL. Mapping the mixed methods-mixed research synthesis terrain. J Mix Methods Res 2012;6:317-31

20. World Health Organization. Noncommunicable disease country profiles. Geneva: World Health Organization; 2011.

21. UNAIDS. HIV and AIDS estimates 2011. Available from: http://www.unaids.org/en/regionscountries/countries/.

22. Averting HIV and AIDS. HIV and AIDS history. Available from: ble at: http://www.avert.org/hiv-aids-history.htm.

23. World Health Organization. History of international policy declarations on Noncommunicable diseases. 2011. Available from: http://www.ghwatch.org/sites/www.ghwatch.org/files/NCDs_Histor yInternationalPolicyDeclarations.pdf.

24. South African National AIDS Council. National strategic plan for HIV, STIs and TB 2012-2016. 2012. Available from: http://laylacassim.co.za/pdf/National\%20Strategic\%20Plan\%20on\%20HIV,\%20STI s\%20and\%20TB.pdf

25. Federal HIV/AIDS Prevention and Control office. Strategic plan Il for intensifying multisectoral HIV and AIDS response in Ethiopia 2010/11-2014/15. Addis Ababa: Federal HIV/AIDS prevention and control office; 2010.

26. Ministry of Health, Malaysia. National Strategy on HIV and AIDS 2011-2015. Available from: http://www.moh.gov.my/images/ gallery/Report/NSP_AIDS_2011_2015.pdf

27. Ministry of Health, Sri Lanka. National HIV Strategic plan Sri Lanka 2013-2017. Available from: http:/hivaidsclearinghouse. unesco.org/search/resources/Sri_Lankan_National_HIV_Strategic _Plan_-_2013-2017.pdf

28. Ministry of Healthcare and Nutrition, Sri Lanka. The national policy and strategic framework for prevention and control of chronic noncommunicable diseases. 2009. Available from: http://www. health.gov.lk/en/NCD/temp/NCD\%20Policy\%20English.pdf

29. Ministry of Health, Malaysia. National strategic plan for noncommunicable diseases: medium-term strategic plan to further strengthen cardiovascular disease and diabetes prevention and control program in Malaysia (2010-2014). Available from: http://www.incd.klinikbistari.com/index.php?view=article\&id=158 \%3Anational-strategic-plan-for-ncd\&format=pdf\&option= com_content\&Itemid=29.

30. Federal Ministry of Health, Ethiopia. Prevention and control of chronic noncommunicable diseases: a strategic framework. Addis Ababa: Ministry of Health; 2010.

31. Gray A, Vawda Y, Jack C. Health policy and legislation. In: Padarath A, English R, eds. South African health review 2012/13. Durban: Health Systems Trust; 2013.

32. Ministry of Health, South Africa. South African strategic plan for the prevention and control of non-communicable diseases 2013-17. Available from: http://www.health-e.org.za/wp-content/uploads/ 2013/09/NCDs-STRAT-PLAN-CONTENT-8-april-proof.pdf

33. Ministry of Health, Malaysia. Country health plan (10th Malaysia Plan): 2011-2015. Available from: https://www.pmo.gov.my/dokume2011;365:876-8. 
nattached/RMK/RMK10_E.pdf

34. Ministry of Health, Ethiopia. Health sector development plan IV: 2010/11-2014/15. Addis Ababa: Ministry of Health; 2010.

35. Health Systems Trust, South Africa. The 10 point plan. Available from: http://www.healthlink.org.za/publications/874

36. Ministry of Healthcare \& Nutrition, Sri Lanka. Health master plan: 2007-2016. Availabke from: http://www.health.gov.lk/en/HMPGuidlines/HMP-07-16/Annual\%20Action\% 20Plan\%202010\%20\%5B Programmes\%20\&\%20Directorates\%5D.pdf

37. Republic of South Africa. Global AIDS response progress report 2012. Available from: http://www.unaids.org/en/dataanalysis/ knowyourresponse/countryprogressreports/2012countries/ce_ZA_ Narrative_Report.pdf

38. Ministry of Health, Malaysia. Malaysia Global AIDS response country progress report 2012. Available from: http://www.unaids.org/ en/dataanalysis/knowyourresponse/countryprogressreports/2012co untries/ce_MY_Narrative_Report.pdf

39. Ministry of Health, Sri Lanka. Sri Lanka global AIDS response progress report, 2012. National STD/AIDS control programme Sri Lanka (2012). Available from: http:/www.aidsdatahub.org/sites/ default/files/documents/UNGASS_2012_SriLanka_Narrative_Repo rt.pdf

40. Federal Democratic Republic of Ethiopia. Country progress report on HIV/AIDS response, 2012. Available from: http:/www.unaids.org /en/dataanalysis/knowyourresponse/countryprogressreports/2012c ountries/GAP\%20Report\%202012.pdf
41. World Health Organization, UNAIDS, UNICEF. Global HIV/AIDS response. Epidemic update and health sector progress towards universal access. 2011 progress report. Available from: http://www. unaids.org/en/media/unaids/contentassets/documents/unaidspublication/2011/20111130_ua_report_en.pdf.

42. The Federal Ministry of Health, ICAP at Columbia University Mailman School of Public Health, The Ethiopian Diabetes Association. Strengthening chronic disease services in Ethiopia: lessons learned from HIV/AIDS program implementation. 2010. Available from: http://www.ghdonline.org/uploads/ICAP_HIVNCD_report_Feb2011.pdf

43. Barouki R, Gluckman PD, Grandjean P, et al. Developmental origins of non-communicable disease: implications for research and public health. Environ Health 2012;11:42.

44. Simon V, Ho DD, Abdool Karim Q. HIV/AIDS epidemiology, pathogenesis, prevention, and treatment. Lancet 2006;368:489-504

45. World Health Organization. Preventing chronic diseases a vital investment. Available from: http://www.who.int/chp/chronic_disease_report/full_report.pdf

46. Haregu TN, Oldenburg B, Setswe G, et al. Epidemiology of comorbidity of HIV/AIDS and non-communicable diseases in developing countries: a systematic review. J Global Healthcare Systems 2012;2.

47. Stevens P. The challenge of noncommunicable diseases in developing countries: lessons from HIV and global health. Available from: http://www.cmpi.org/uploads/File/non-communicable-diseases.pdf. 